\title{
All-optical signal processing of OTDM and OFDM signals based on time-domain optical fourier transformation
}

\author{
Galili, Michael; Guan, Pengyu; Lillieholm, Mads; Hu, Hao; Oxenløwe, Leif Katsuo
}

Published in:

Signal Processing in Photonic Communications 2017

Link to article, DOI:

10.1364/SPPCOM.2017.SpW3F.3

Publication date:

2017

Document Version

Peer reviewed version

Link back to DTU Orbit

Citation (APA):

Galili, M., Guan, P., Lillieholm, M., Hu, H., \& Oxenløwe, L. K. (2017). All-optical signal processing of OTDM and OFDM signals based on time-domain optical fourier transformation. In Signal Processing in Photonic Communications 2017 (Vol. 2017). Optical Society of America (OSA).

https://doi.org/10.1364/SPPCOM.2017.SpW3F.3

\section{General rights}

Copyright and moral rights for the publications made accessible in the public portal are retained by the authors and/or other copyright owners and it is a condition of accessing publications that users recognise and abide by the legal requirements associated with these rights.

- Users may download and print one copy of any publication from the public portal for the purpose of private study or research.

- You may not further distribute the material or use it for any profit-making activity or commercial gain

- You may freely distribute the URL identifying the publication in the public portal 


\title{
All-optical Signal Processing of OTDM and OFDM Signals based on Time-domain Optical Fourier Transformation
}

\author{
Michael Galili, Pengyu Guan, Mads Lillieholm, Hao Hu, Leif Oxenløwe \\ Technical University of Denmark, Department of Photonics Engineering - DTU Fotonik, Kgs. Lyngby, DK-2800, Denmark \\ mgal@fotonik.dtu.dk
}

\begin{abstract}
In the talk, we will review recent work on optical signal processing based on time lenses. Various applications of optical Fourier transformation for optical communications will be discussed. OCIS codes: (060.2330) Fiber optics communications; (060.4370) Nonlinear optics, fibers; (070.4340) Nonlinear optical signal processing
\end{abstract}

\section{Introduction to the presentation}

A key challenge in optical communication systems today is the relentless demand for increasing data capacity and the resulting demands for more energy-efficient communication technologies. Scaling current technologies to meet projected traffic demands will result in extensive parallelism. In that scenario, scaling the bandwidth will also scale the number of components and net power consumption. This is motivating intense research effort into developing technologies, which may allow for increased capacity with reduced energy consumption. Nonlinear optical signal processing may in some cases offer very high bandwidth processing at a comparatively lower energy consumption. However, the largest potential in optical signal processing appears to be in functionalities where the number of signal processing steps is low, and where the signal processing itself is simple. Complex digital logic has so far turned out to be challenging to implement in optics, format conversions or Fourier transformations turn out to be quite simple to implement optically. An extremely attractive tool for many of these conversions is the optical time lens.

In this talk we will outline several recent applications of time lenses to perform signal processing which would otherwise be very challenging to achieve. We will show that with quite simple time lens implementations complex signal processing can be achieved.

The concept of a "time lens" is a useful abstraction introduced by B. H. Kolner in 1994 to describe the parallel formulation of diffractive imaging and dispersive propagation. In both cases, an image is generated corresponding to the Fourier transform of the original object in the 'far field' of the system. In diffractive optics this results in the creation of an image corresponding to the Fourier transform of the object that shaped the diffracted wave e.g. an aperture. In dispersive propagation this results in the creation of an 'image' in the time domain corresponding to the Fourier transform of the time domain shape of the dispersed wave. These two parallel formulations are illustrated in Figure 1. In both cases, lenses can be applied to focus the generated image.
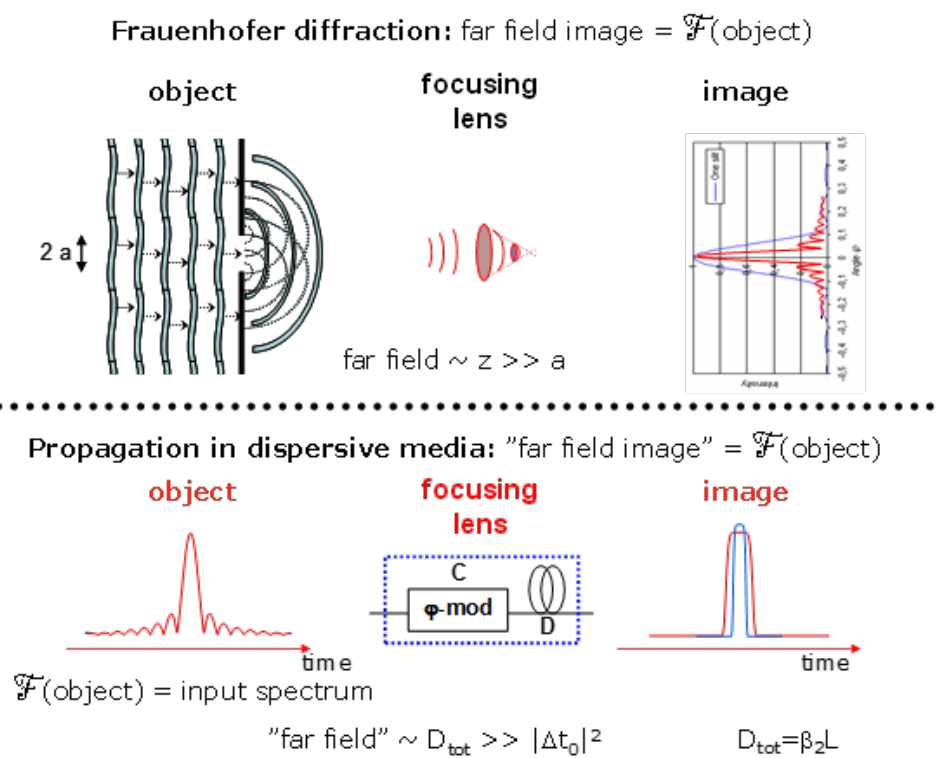

Figure 1 - Illustration of the parallel formalism for diffractive and dispersive Fourier transformation. 
In the 'time lens' case, the equivalent of a lens is a time dependent phase shift applied to the field. To achieve undistorted focusing of the image the phase shift must be quadratic as function of time. For many applications the required phase shift is significant and may be difficult to achieve by means of conventional electro-optical phase modulation. As an alternative a quadratic phase shift can be created by four wave mixing (FWM) with a linearly chirped pump pulse. This is illustrated Figure 2. In order to achieve only phase modulation the amplitude of the pump pulse is kept constant for the duration of the interaction with the signal. The generated idler wave will thus acquire a phase shift proportional to the time-integral of the frequency change of the pump, according to: $\Delta \omega=\partial \phi / \partial t$. The use of FWM as a means of generating strong phase modulation has several advantages. It is ultra-fast and allows for great flexibility in the magnitude and duration of modulation. It does, however, also require very broadband FWM to minimize signal distortions and it is typically associated with a change in signal wavelength.

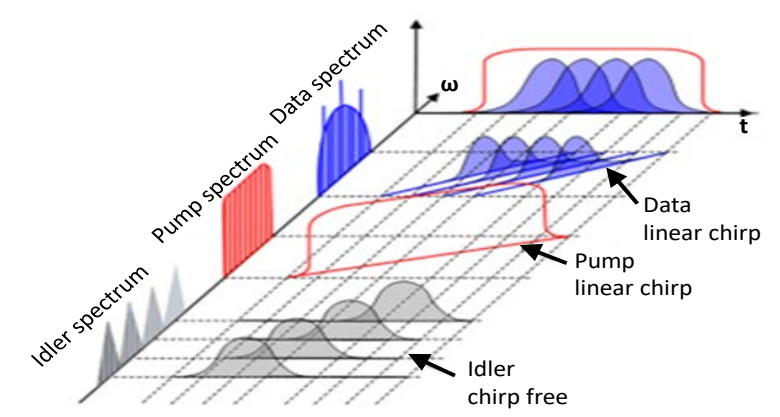

Figure 2 - Illustration of FWM used to apply phase modulation to an already chirped data signal. Chirp and phase modulation are matched to create a chirp free idler.

In the talk we will review the details of implementation of the time lens as well as several examples of applications. We will highlight applications to serial-parallel conversion and implementations for 'complete' optical Fourier transforms where both time- and frequency domains for transformed. 